\title{
Ultrasound Guided Serratus Plane Block for Post- Mastectomy Pain Syndrome after Mastectomy with Axillary Node Dissection
}

\author{
Matteo Bossolasco* and Lucia Maria Fenoglio \\ Department of Anesthesiology and Intensive Care, ASL CN1, Savigliano
}

Submission: May 08, 2017; Published: June 06, 2017

*Corresponding author: Matteo Bossolasco (M.D.), Department of Anesthesiology and Intensive Care. ASL CN1, Via Ospedali, 14, Savigliano. Cuneo, Italy, Tel: 0172/719111; Email: matteo.bossolasco@gmail.com

\begin{abstract}
Post-mastectomy pain is common and can be difficult to manage. Studies estimate that post-mastectomy pain syndrome develops in about $25 \%$ to $60 \%$ of women, leading to disability, psychological distress, and diminished quality of life. Here we described a 2 cases of (PMPS) successfully treated with single shot ultrasound guided deep serratus plane block.
\end{abstract}

Keywords: PMPS; Serratus Plane Block; Ultrasound; Pain

Abbreviations: PMPS: Post-Mastectomy Pain Syndrome; NRS: Numerical Rating Scale; NSAIDs: Nonsteroidal Anti-Inflammatory Drugs; SPB: Serratus Plane Block.

\section{Introduction}

Breast cancer is the most common cancer among women of all races. In 2017, it's estimated that 127 new cases per 100,000 women will be diagnosed in the United States alone [1]. Thirtysix percent of those diagnosed with stage I or II breast cancer undergo mastectomy and $72 \%$ of those diagnosed with stage III will [2].

Breast cancer treatment besides surgical procedures includes adjuvant radiation treatment, chemotherapy, and endocrine therapy, all of which carry an increased risk of postoperative pain. Post-mastectomy pain is common and can be difficult to manage.

Studies estimate that Post-Mastectomy Pain Syndrome PMPS develops in about $25 \%$ to $60 \%$ of women [3], leading to disability, psychological distress, and diminished quality of life. There is no standardized definition for PMPS it has been described as a type of neuropathic pain, a complex chronic pain state commonly associated with nerve fiber injury [4-5]. Pain is typically localized to the anterior/lateral chest wall, maxilla, and/or medial upper arm and persists more than 3 months after surgery when all other causes of pain have been excluded [6]. Post-mastectomy pain is characterized by the classic features of neuropathic pain such as burning, tingling, shooting, stinging, or stabbing pains, and hyperesthesia.
A recent systematic review of the literature [7] found that noninterventional and interventional treatments have been proposed for PMPS, but that the majority of the studies lacked descriptive information and clear reports of statistical tests.

Though the review did not evaluate studies on the use of regional analgesia, the Serratus Plane Block (SPB) is gaining popularity for treating (PMPS).

\section{Case One}

A 71-year-old woman with moderate hypertension, wellcontrolled non-insulin-dependent diabetes mellitus, and a history of left breast lumpectomy, underwent left mastectomy with axillary node clearance under general anesthesia with postoperative infiltration of the surgical wound by the surgeon at the end of the operation.

During the postoperative period she reported mild, mainly axillary pain rated from 2 to 4 on an 11-point numerical rating scale (NRS) for pain. She was treated with non steroidal antiinflammatory drugs (NSAIDs) and tramadol. Fifteen days after discharge from the hospital, she was referred to a pain clinic because of axillary pain with multiple daily exacerbations and dysesthesia in the left axilla. Initial treatment with oral NSAIDs, pregabalin, tramadol daily with oral administration of morphine 
sulphate (Oramorph ${ }^{\circledR}$ ) for breakthrough pain was unsuccessful. The pain gradually worsened, causing physical limitation and anxiety. Radiographic studies were unremarkable. The pain severity increased to 8-9 as measured on the NRS and was described as burning and shooting pain. In discussions with the patient, we proposed an ultrasound-guided, single shot deep SPB as done with the technique described in our previous report [8].

The left arm was gently abducted, a linear ultrasound probe (high frequency linear probe connected to MyLabTM Alpha, Esaote, Genova, Italy), was placed in the sagittal plane over the midclavicular region of the left chest wall. The ribs were counted; the fifth was identified and followed laterally towards the midaxillary line, and the site was then marked. The right side of the chest was prepared by disinfecting the skin with a chlorhexidine $0.5 \%$ in alcohol $70 \%$ antiseptic, and a sterile cover was applied over the probe. With the patient in supine position, the ultrasound probe was placed along the midaxillary line on the landmark at the level of the fifth rib. In this way, we were able to identify, from the surface inwards, the latissimus dorsi, the serratus anterior muscle, the ribs, and the pleura.

At the caudal extremity of the probe, the skin entry point and subcutaneous tissues were anesthetized with $4 \mathrm{~mL}$ of $1 \%$ lignocaine. Under real-time ultrasound guidance, a $50 \mathrm{~mm}$ 22-gauge needle (Pajunk, Geisingen, Germany), was positioned with an in-plane technique in caudocranial direction between the surface of the rib and the serratus anterior muscle (Figure 1) and a total of $10 \mathrm{~mL}$ of LA $(7 \mathrm{~mL}$ of ropivacaine $0.25 \%+3 \mathrm{~mL}$ of lignocaine $1 \%$ ) plus dexamethasone $4 \mathrm{mg}$ were then injected. Ten minutes later, the NRS score decreased from 10 to 1 the patient was able to move her left upper arm without major limitation she was discharged home and instructed to continue with pregabalin therapy. Fifteen days later, the patient reported experiencing recurrence of pain (NRS score 5to7). A second SPB was performed as described previously. Three months after this last block she remains pain free and is able to carry out daily physical activities without major limitations.

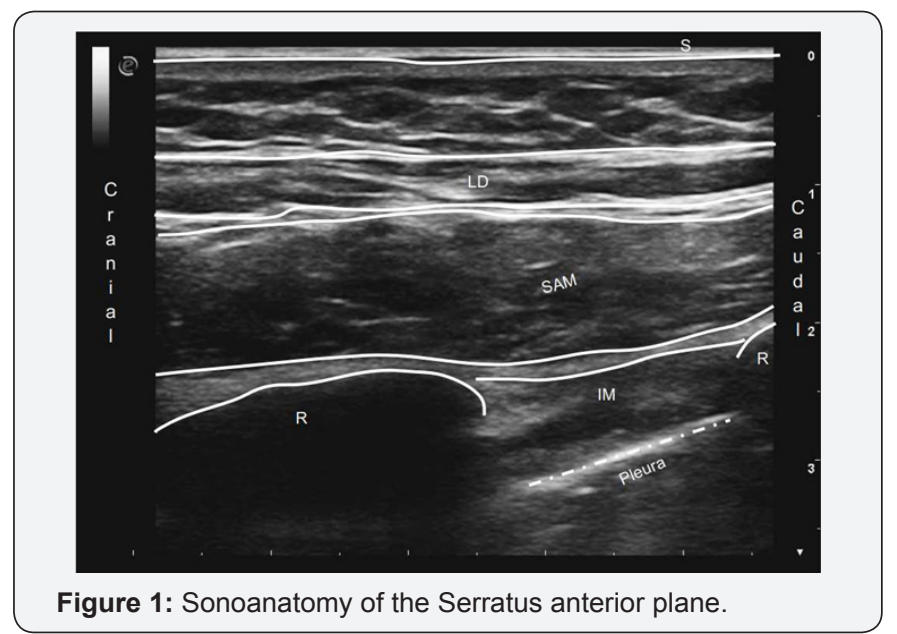

S: Skin, LD: Latissimus Dorsi Muscle, SAM: Serratus Anterior Muscle, IM: Intercostal Muscle, R: Rib.

\section{Case Two}

A 43-year-old woman in otherwise good health underwent left mastectomy with skin expander implantation plus axillary node dissection under general anesthesia plus pectoral nerves (PECS I+II) block. Starting the second postoperative day, she reporteed moderate pain (NRS score of 5) iv morphine and NSAIDs were administered, and the pain regressed. She was discharged with a prescription of acetaminophen if needed.

Four months later, she was readmitted because of intense left thoracic pain. Radiographic studies were normal. Ten minutes after the SPB was performed (as described above), the pain severity was rated as 2 on the NRS. She was discharged with a prescription for pregabalin $75 \mathrm{mg}$ twice a day + tramadol $200 \mathrm{mg} /$ die. At the follow-up visits planned at 15 and 40 days postoperative, two SPBs were performed because of pain rated as 6 and 4, respectively, on the NRS. Oral therapy was continued. At 6 months after the first (SPB), the pain was rated 1 on the (NRS), without causing any limitation of physical activity.

\section{Discussion}

The serratus anterior is a broad flattened sheet of muscle originating from the first nine ribs and passes posteriorly around the thoracic wall before inserting into the costal surface of the medial border of the scapula [9] Blanco first described [10] and identified the serratus plane as a potential space in which the branches of the intercostals nerves run within two potential spaces, one superficial and one deep to the serratus anterior muscle itself.

Since then, SPB has been used mainly for postoperative analgesia in ipsilateral thorax [11] more recently for posttraumatic pain relief [8] and for (PMPS) in a few cases [12].

The serratus muscle is superficial, so his ultrasound identification, essential for the (SPB), is relatively easy. No major complications have been reported in the literature; continuous visualization of the pleura and accurate control of needle trajectory/tip are essential to minimize the risk of potentially serious complications.

\section{Conclusion}

These two cases demonstrate the efficacy of ultrasoundguided deep (SPB) as a multimodal treatment for patients with (PMPS). Although this technique holds promise, further studies are needed to assess the real efficacy, potential adverse effects, and complications of (SPB) for (PMPS).

\section{References}

1. U.S. Cancer Statistics Working Group. United States Cancer Statistics: 1999-2013 Incidence and Mortality Web-based Report Atlanta: U.S Department of Health and Human Services, Centers for Disease Control and Prevention and National Cancer Institute 2016.

2. Miller KD, Siegel RL, Lin CC, Mariotto AB, Kramer JL, et al. (2016) Cancer treatment and survivorship statistics, 2016. CA Cancer J Clin 66(4): 271-289. 
3. Andersen KG, Kehlet H (2011) Persistent pain after breast cancer treatment: a critical review of risk factors and strategies for prevention. J Pain 12(7): 725-746.

4. Granek I, Ashikari R, Foley K (1984) The post-mastectomy pain syndrome: clinical and anatomical correlates. Proc Am Soc Clin Oncol 3: 122 .

5. Foley KM (1987) Pain syndromes in patients with cancer. Med Clin North Am 71(2): 169-184.

6. Stevens PE, Dibble SL, Miaskowski C (1995) Prevalence, characteristics, and impact of postmastectomy pain syndrome an investigation of women's experiences. Pain 61(1): 61-68.

7. Larsson I M, Ahm Sorensen J and Bille C (2017) The Post-mastectomy Pain Syndrome A Systematic Review of the Treatment Modalities. Breast J 23(3): 338-343.

8. Bossolasco M, Bernardi E, Fenoglio LM. (2017) Continuous serratus plane block in a patient with multiple rib fractures. J Clin Anesth 38: 85-86

This work is licensed under Creative

Commons Attribution 4.0 License

DOI: 10.19080/JAICM.2017.03.555604
9. Drake RL, Vogl W, Mitchell AWM (2010) Gray's anatomy for students. Philadelphia Elsevier Inc (2nd edn): 633-647.

10. Blanco R, Parras T, McDonnell J G and Prats-Galino A (2013) Serratus plane block: a novel ultrasound-guided thoracic wall nerve block Anaesthesia 68(11): 1107-1113.

11. Abdallah FW, MacLean D, Madjdpour C, Cil T, Bhatia A, et al. (2017) Pectoralis and Serratus Fascial Plane Blocks Each Provide Early Analgesic Benefits Following Ambulatory Breast Cancer Surgery A Retrospective Propensity-Matched Cohort Study, Anesth Analg.

12.Zocca JA, Chen GH, Puttanniah VG, Hung JC and Gulati A (2017) Ultrasound-Guided Serratus Plane Block for Treatment of Postmastectomy Pain Syndromes in Breast Cancer Patients: A Case Series. Pain Pract 17(1): 141-146.

\section{Your next submission with Juniper Publishers will reach you the below assets}

- Quality Editorial service

- Swift Peer Review

- Reprints availability

- E-prints Service

- Manuscript Podcast for convenient understanding

- Global attainment for your research

- Manuscript accessibility in different formats

( Pdf, E-pub, Full Text, Audio)

- Unceasing customer service

Track the below URL for one-step submission https://juniperpublishers.com/online-submission.php 